\section{La enseñanza canónica de la Historia. De la forja de la conciencia nacional a la historia del hombre en sociedad}

Recibido: Enero de 2017 | Aprobado: Marzo de 2017

\section{Resumen}

Desde hace siglos, la historia ha sido tergiversada por los Estados en interés de los poderes políticos imperantes en cada momento. Es el denominado canon histórico. El objetivo de este artículo no es otro más que arrojar luz en primer lugar sobre el impacto de la enseñanza canónica de la historia, explicar los efectos que causa su inclusión en los currículos, incluso actuales, con una aproximación a su génesis, para posteriormente entrar en la alternativa actual de la didáctica de la historia, tanto desde el punto de vista teórico como práctico, con especial atención al factor cognitivo, es decir, a cómo se crea el conocimiento histórico, esencial para comprender el hecho histórico. En el fondo, el afán que impulsa este artículo es ser de utilidad, que sea una propuesta para los docentes que quieren que la asignatura de Historia sea atractiva y útil para sus discentes.

Palabras clave Canon Histórico, Nueva Historia, Historia Social, Cognitivismo, Pensamiento Crítico.
Ernesto Ferrando Llimós

Es Doctor en Historia de la Universidad Pablo de Olavide, Sevilla (España) e investiga sobre la enseñanza del arte y la historia de España para alumnos extranjeros. Su artículo más reciente se titula "Propuestas metodológicas para el diseño de un curso de lengua extranjera basado en el enfoque por tareas. Análisis de necesidades, seleccióny tipos de tareas", en: Trabalhos em Lingüística Aplicada 3 (2017),801-837.ernesto_ferrando_llimos@yahoo.es
The Canonical Teaching of History. From the Forging of National Consciousness to the Men's History in Society

\begin{abstract}
For centuries, states have distorted History with the intention to defend the narratives of the prevailing political powers in each moment. It is the so-called historical cannon. This article seeks to shed light on the impact of canonical teaching on history, offering an approximation to its genesis and explaining the effects of its inclusion in the curricula. Then, the article discusses current alternative didactics to teach history, both from the theoretical and practical point of view, with special attention to the cognitive factor that is, how the historical knowledge is created, and essential to understand the historical fact. At the end, this article pretend to be a useful proposal for teachers who want to show historic subjects both as attractive and useful to their students.
\end{abstract}

\section{Keywords}

Historical Cannon, New History, Social History, Cognitivism, Critical Thinking. 


\section{Presentación}

El presente trabajo es una aproximación a la actual didáctica de la historia. En primer lugar, se expondrá de forma conceptual la idea de canon histórico, con especial atención al motivo de su aparición, sus principios educativos e influencia en los currículos académicos. Posteriormente, se plantearán las bases teóricas para un nuevo paradigma de la educación en Historia para el siglo XXI, una alternativa a la enseñanza canónica, prestando atención a los nuevos enfoques nacidos a raíz de la aparición de la Nueva Historia en los años 70, su aplicación en clase con propuestas didácticas concretas con vistas a crear un método que no solo haga de la Historia una asignatura más cercana a los intereses de los alumnos, sino que despierte en ellos la curiosidad de la investigación histórica, de comprender el hecho histórico, ya no de memorizarlo, de construir conocimiento nuevo, rico y sin manipulación alguna, respetando todas opiniones, incentivando la empatía y la comprensión del otro.

\section{El canon histórico. Aproximación conceptual}

La historia, como reina de las Ciencias Sociales, ha tenido desde los inicios de la civilización un papel relevante como medio transmisor de valores morales, de muestrario de hechos señeros, forjadores de naciones y modelo para generaciones presentes y futuras. Desde sus principios como materia curricular en los países occidentales durante el siglo XIX, y en adelante, la enseñanza de la historia se ha visto claramente influida por la política. El nacionalismo, la región o la política se han mezclado a lo largo de los tres últimos siglos para formar un canon histórico, un Gran Relato de carácter etnocentrista y por ende excluyente, el cual ha marcado el camino de infinidad de textos, libros o métodos.

Ya desde los tiempos de los primeros filósofos, las Ciencias Sociales cobran sentido como materia moralizante; en la propia República de Platón el filósofo ateniense habla de la moralidad de los distintos grupos que conforman la polis, y de lo que aportan cada uno de ellos a la sociedad, siendo el papel del historiador el de moralista. ${ }^{2}$ Posteriormente, en la Edad Media y Moderna será la moral cristiana la que cobre un total protagonismo cuando la historia venga marcada por el modelo teológico agustiniano, teocentrista, con una visión lineal del tiempo, que iba desde el Cénesis hasta el Apocalipsis, ${ }^{3}$ frente a la cíclica historia griega. Y será a través de esta moral como el historiador, o el artista, interpretará los fenómenos históricos, y no será hasta el Renacimiento cuando la historia se deshace de sus ataduras apareciendo la crítica histórica y la erudición. ${ }^{4}$

1 Linda Symcox y Arie Wischut (eds); National History Standards. The problem of the Canon and the Future of teaching History, Alabama, Universidad de Alabama, 2009, p. 1.

2 Amparo Alcaraz y Montserrat Pastor, "Tendencias de la historia como objeto de enseñanza a través de la Historiografía", en Didácticas Específicas, $n^{0}$ 6, Madrid, Universidad Autónoma de Madrid, 2012, p. 2. Recuperado de: https://repositorio.uam.es/ bitstream/handle/10486/10852/54136_6.pdf?sequence $=1$

3 Alcaraz y M. Pastor, "Tendencias de la historia como objeto de enseñanza a través de la Historiografía”, p. 3.

4 Gemma Tribó, Enseñar a pensar históricamente. Los archivos y las fuentes documentales en la enseñanza de la historia, Barcelona, Cuadernos del profesorado. I.C.E Universidad de Barcelona, 2005, p. 44. 
Con la llegada de la Ilustración, en el siglo XVIII, deviene un gran cambio en la mentalidad del ser humano; es una época de descubrimientos científicos, de reyes ilustrados, de secularización, y sobre todo de una nueva conciencia nacional. Y será durante la Ilustración, cuando se fijen las bases del conocimiento histórico moderno, basado en la necesidad de estudiar los hechos de la nación. ${ }^{5}$ Durante la llustración aparece también el primer patriotismo liberal, de inspiración racionalista, el cual contrapondrá la razón común a la tradición y la voluntad colectiva al peso de las instituciones y costumbres heredadas. ${ }^{6}$ Además, aparecen los estados-nación, de carácter liberal, que se verán definitivamente consolidados en el siglo siguiente. Será en este momento cuando la historia aparece en el escenario educativo ligada a la formación de estos estados nacionales. ${ }^{7}$ Ya durante el siglo XIX, en pleno positivismo y nacionalismo burgués, en casi todos los países occidentales se incorpora la historia como materia, tanto en la primera como en la segunda enseñanza, a la vez que se crean los estudios universitarios de dicha especialidad. ${ }^{8}$ Con la conformación de estos estados, crece la necesidad de la formación de una identidad

5 Sebastián Molina, Raimundo Rodríguez, Raquel Sánchez, "Investigar, enseñar y divulgar la historia social: la experiencia del Seminario y grupo de investigación Familia y Élite de Poder de la Universidad de Murcia”, en Proyecto Clío $n^{\circ} 39$, Murcia, Universidad de Murcia, 2013, p. 3. Recuperado de http://clio.rediris.es/n39/ articulos/historiasocial/MolinaRodriguezSanchez.pdf

6 Ramón Facal, "La enseñanza de la historia, más allá del nacionalismo", en Ponencias del VI Congreso de la Asociación de Historia Contemporánea, Zaragoza, Universidad de Zaragoza, 2002, p. 21. Recuperado de http://www.histodidactica.es/articulos/lopezfacal.htm

7 Joaquín Prats, En defensa de la Historia como materia educativa, Barcelona, Departament de Didàctica de les Ciències Socials, Universidad de Barcelona, 2010, p. 91.

8 J. Prats, En defensa de la Historia como materia educativa, p.91. nacional en donde los antiguos súbditos son ahora ciudadanos-sujetos. ${ }^{9}$ Aparece con ello lo que Hobsbawn denominó como principio de las nacionalidades en lo concerniente al papel de ese nuevo ciudadano de ese estado-nación, el cual se diferencia del "otro", el ciudadano de otra nación, por compartir de forma homogénea con los suyos un territorio y una cultura propia, una patria, en definitiva. De este modo fueron apareciendo modelos pedagógicos cuyos objetivos no eran otros que hacer de la historia un medio de internalizar una identidad colectiva mediante la emisión de símbolos para el refuerzo de los sentimientos de pertenencia a una comunidad. ${ }^{10}$

Por su lado, ya en pleno siglo XX, en 1926, el pedagogo alemán Richard Seyfert indicará, quizás influido por la sangrienta exaltación nacionalista de la la Guerra Mundial, que el objetivo de la historia no era otro que despertar el sentimiento nacional. ${ }^{11}$ Pero también el siglo XX vivió un gran cambio en la epistemología de la historia. Aparecen los Annales como revisión de la teoría de la historia propuesta por el Marxismo. Con la aportación de la Escuela de los Annales la historia deja atrás el positivismo factual políticomilitar anterior, para dar paso a la historia social y económica. ${ }^{12}$

9 Paula Gonzales, "Conciencia histórica y enseñanza de la historia: una mirada desde los libros de texto", en Enseñanza de las Ciencias Sociales $n^{\circ}$. 5, Barcelona, Universidad de Barcelona, 2006, p. 21. Recuperado de http://www.redalyc.org/pdf/3241/324127625003.pdf 10 P. Gonzales, “Conciencia histórica y enseñanza de la historia”, p. 22. 11 Joaquín Prats, Enseñar Historia: notas para una didáctica renovadora, Mérida, Junta de Extremadura. Dirección General de Ordenación, Renovación y Centros, 2001, p. 91.

12 G. Tribó, Enseñar a pensar históricamente. Los archivos y las fuentes documentales en la enseñanza de la historia, p.45. 
Tras los visto, el relato histórico de exaltación nacionalista, el relato identitario, se puede decir basado en los grandes personajes, batallas, descubridores o santos ${ }^{13}$ nacido en el siglo XVIII, marcará el paradigma educativo, lo que se denomina como canon histórico, o El Gran Relato histórico, el cual pautará los planes educativos en los siguientes siglos, hasta llegar incluso a los tiempos actuales. Por lo tanto, la intención de este canon, como se infiere, será configurar la conciencia de los ciudadanos, ${ }^{14}$ como sistema para afianzar y legitimar el poder ${ }^{15} y$ formar la conciencia patriótica. ${ }^{16}$

Su aplicación en las aulas girará en torno a la memorización-repetición de lugares, nombres y fechas, con el agravante de que debido a una falta de consistencia académica, de buenos profesionales, la historia cambia según las modas; después de todo se interpreta el pasado desde el mismo presente. ${ }^{17}$ Es importante remarcar este último punto puesto que efectivamente las modas - y las tendencias políticas del momento - marcan el modo de entender la historia. Para el historiador Ricardo García Cárcel del secuestro de Clío por parte de los políticos de tiempos pasados, según se ha visto, se ha pasado a un nuevo secuestro: el hacer historia desde el

13 Sebastián Molina, Raimundo Rodríguez y Raquel Sánchez, "Investigar, enseñar y divulgar la historia social: la experiencia del Seminario y grupo de investigación Familia y Élite de Poder de la Universidad de Murcia”, en Proyecto Clío n³9, Murcia, Universidad de Murcia, 2013, p. 4. Recuperado de http://clio.rediris.es/n39/ articulos/historiasocial/MolinaRodriguezSanchez.pdf

14 J. Prats, Enseñar Historia: notas para una didáctica renovadora, p. 91.

15 J. Prats, En defensa de la Historia como materia educativa, p.2.

16 S. Molina, R. Rodríguez y R. Sánchez, "Investigar, enseñar y divulgar la historia social", p.4.

17 S. Molina, R. Rodríguez y R. Sánchez, "Investigar, enseñar y divulgar la historia social", p.285. presente. Aparece el historiador-político que instrumentaliza la historia desde el paradigma del presente. El presente deja de ser el legado de la historia para convertirse en su motor. ${ }^{18}$

\subsection{El canon histórico: principios educativos}

En el epígrafe anterior se ha visto como la historia, y su didáctica, se ha basado hasta los tiempos actuales en un canon que variaba según el momento histórico por intereses políticos, económicos, sociales, etc., como medio para justificar los valores morales y políticos del momento. No obstante, merece la pena profundizar para ver hasta qué punto el canon afecta a la estructura interna de un programa dirigido a enseñar historia, cómo su presencia mediatiza la aprehensión de nuevos conocimientos.

La historiadora e investigadora canadiense Hanna Schissler ${ }^{19}$ indica en qué medida el canon influye con su presencia, tanto en el contexto social como político, centrándose en cinco aspectos:

- La consolidación y codificación. Schissler hace mención al físico e historiador norteamericano Thomas Kuhn cuando describió que las revoluciones en la organización del conocimiento ocurren cuando el paradigma vigente es desplazado por otro, creando con ello un desequilibrio en los conceptos académicos.

18 Ricardo García, La Herencia del pasado. Las memorias históricas de España, Barcelona, Galaxia Gutenberg - Círculo de Lectores, 2011, p.30.

19 L. Symcox y A. Wischut, National History Standards, p. 95. 
Esto ocurre una vez tras otra, como un proceso de violenta contención, a veces debida a la resistencia de los "guardianes de la verdad", según el propio Kuhn. En el fondo esto recuerda el constructivismo, cuando habla del cambio de esquemas del conocimiento caracterizado por el equilibrio inicial (o conflicto inicial) - desequilibrio - reequilibrio posterior, y de la importancia de éste a la hora de crear conocimiento ${ }^{20}$. Las enciclopedias del siglo XVIII, como indica la autora, son un claro ejemplo de ambas cosas; mientras que la consolidación del conocimiento es un hecho positivoy deseable, la codificación, en cambio, tiende a crearel canon, o sea, a aislary petrificar el conocimiento. Sin ese desequilibrio no hay conocimiento. Se desprende de todo ello que estos "guardianes" son los poderes imperantes en cada momento histórico. Schissler, a su vez, pone como ejemplo el comportamiento de la iglesia católica en el caso de Galileo Galilei: la Iglesia no podía rebatir a Galileo, no tenía argumentos científicos, pero sí podía prohibir su teoría.

- El canon como esquema limitado de conocimientos. Durante el siglo XVIIIeran los eruditos de las nacientes academias quienes decidían quién era considerado ilustrado y quién no y por ende qué conocimientos, para ser considerado ilustrado, debía tener. Por ejemplo, en el arte fue especialmente gravoso el uso que las academias hicieron del denominado como canon artístico. El canon se convirtió en un "vigilante" contra

20 César Coll, Elena Martín, Teresa Mauri, Mariana Miras, Javier Onrubia y Isabel Solé, El Constructivismo en el aula, Barcelona, Editorial Grao, 1998, p. 81. las corrientes contemporáneas, como el postmodernismo. En definitiva, la limitación de los conocimientos mediante reglas impuestas impide la entrada de nuevas ideas; por ejemplo la consideración en la didáctica de la historia de los movimientos sociales, el papel de las minorías, de las mujeres, los valores para la paz, etc.

- El canon como idea autoritaria. Ya se ha visto que desde el siglo XVIII ha sido el Estado quien ha marcado las pautas de los contenidos en la asignatura de Historia. El canon representa la expresión de los valores de unas élites sociales, culturales, políticas o económicas que gobiernan esos Estados. De lo que se desprende que no cabe propuesta alguna a la construcción del Estado al margen de estas élites.

- El canon en su papel de contención. El canon evita la "amenaza" de las nuevas ideas, las filtra y las metaboliza.

- Mediante el canon se decide la relevancia del conocimiento. Pese a que es muy difícil decidir cuál es el conocimiento más importante según el momento histórico.

\section{Hacia un nuevo paradigma. La alternativa a la enseñanza canónica de la historia}

\subsection{La enseñanza de la Nueva Historia.}

La socióloga irlandesa Carmel Gallagher proporciona un comentario que sirve como punto de referencia a este epígrafe. Este comentario fue 
publicado en su estudio sobre la enseñanza de la Historia y su valor como medio para promocionar los valores democráticos, el cual nos dice:

Call for the abandonment of national and military history and its replacement by an emphasis on economic, cultural and social history. History should be taught so that it shows the unfolding of a spirit of world community, leading to a world state and resulting in people identifying themselves not as national citizens but as members of the human species. ${ }^{21}$

Por su lado, John Torpey en su artículo The Pursuit of the Past: A Polemical Perspective, argumentó que era la visión del futuro de las naciones estado o del proletario internacional los que hicieron tan poderosa la narrativa del nacionalismo o del socialismo. Y que además, a estos dos puntos debemos añadir esa visión, tan ilustrada por otra parte, de un futuro en constante progreso para el ser humano. No obstante el colapso de esta visión, que del futuro se tenía, fue la causante de la crisis de nuestra conciencia

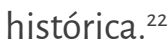

En otras palabras: tanto el colapso del comunismo como el descrédito de la idea de una nación estado con su peligrosa orientación hacia los nacionalismos, que tantas guerras han generado, trajeron una nueva visión de un futuro no tan idílico y con ello el fin de muchos mitos y la llegada del Postmodernismo. Con

21 Carmel Gallagher, History teaching and the promotion of democratic values and tolerance, Bruselas, Council of Europe, 1996, p. 24.

22 John Torpey, The Pursuit of the Past: A Polemical Perspective, Vancouver, University of British Columbia, 2001, Pp. 3-7. el Postmodernismo aparece el relativismo y la pluralidad, y con ello se auspicia el respeto a la diversidad y se presta atención a gran cantidad de voces pertenecientes a multitud de culturas, subculturas, grupos sociales minoritarios y personas individuales, y no a una única voz o un único relato o una única historia universal. ${ }^{23}$ No obstante, esta nueva visión de la historia no anda pareja en todas las naciones, aunque marcó el principio de un gran cambio, un cambio que se debe ubicar en el Reino Unido de los años 70.

Durante los años 1960 y 1970 la enseñanza de la historia vivió su despolitización, al menos en los países occidentales, por lo que para estos tiempos que corrían la vieja enseñanza de la Historia, basada justamente en el canon histórico de alto valor político, tenía poco sentido. ${ }^{24}$ Los profesores comenzaron a desarrollar nuevos métodos para hacer que la Historia fuera útil; la despolitización en el fondo había causado un efecto quizás inesperado ya que la asignatura de Historia se había vuelto inútil para los poderes políticos, y con ello parecía irremediable su desaparición. Además, durante estos años se pensaba que las Ciencias Sociales eran más prácticas para entender tanto la sociedad, y sus rápidos cambios, como la misma naturaleza humana; eran tiempos en que los estudiantes se planteaban preguntas tales como "icómo puede algo ocurrido antes de la carrera espacial enseñarme a arreglármelas." ${ }^{25}$ Por lo tanto, el

23 Cristóbal Ruiz, La Educación en la sociedad postmoderna: Desafíos y oportunidades, Málaga, Universidad de Málaga, 2009, p. 5. Recuperado de https://revistas.ucm.es/index.php/RCED/article/ viewFile/RCED1010120173A/15238

24 L. Symcox y A. Wischut, National History Standards, p. 3.

25 L. Symcox y A. Wischut, National History Standards, p. 2. 
cambio en la enseñanza de la historia viene ligado a la crisis de un modelo de sociedad.

En octubre de 1968 salió publicado en la revista de la Historical Association un artículo de Mary Price cuyo título era más que elocuente: History in danger. La autora con este título vino a expresar sus temores sobre la posibilidad de que la asignatura de Historia desapareciera subsumida, como una asignatura más, dentro de las denominadas Ciencias Sociales. En aquella época numerosos profesores de Historia del Reino Unido se veían obligados a impartir sus clases partiendo de los cambios que en los currículos se estaban llevando a cabo. Para muchos de estos profesores esta nueva tendencia significaba el fin de la asignatura, y el artículo de Price vino a dar visibilidad a esta inquietud; pese a que para muchos el título era demasiado catastrofista. ${ }^{26}$ Pese a todo, el artículo sirvió como acicate para que no pocos profesionales de la materia se pusieran manos a la obra en busca de una nueva metodología que hiciera de la Historia una asignatura con derecho propio.

Para muchos docentes, en el fondo, el problema era más simple: ¿cómo hacer que la historia interese a los alumnos? Qué duda cabe que cuando una cosa deja de ser interesante, se dice que deja de ser útil, desaparece. Pero con la Historia no podía pasar esto. El artículo, como se apuntó, sirvió después de todo para algo puesto que se acordaron reuniones periódicas de la Asociación con vista a buscar soluciones al problema planteado. Había que desarrollar una metodología para la asignatura de Historia que

26 M. Price, "History in Danger," en History Vol. LIII (1968), pp. 342-347. evitara la aburrida memorización de contenidos, de relatos pasados que poco o nada tenían quever con el presente, al menos para el discente. Pese a la oposición inicial de las autoridades educativas, en 1972 el Schools Council creó el Proyecto 13-16 para la enseñanza de la Historia.

El proyecto, dirigido por David W. Sylvester, hizo su rodaje en la Universidad de Leeds, para al poco tiempo ser aprobado y puesto en práctica en más centros del país. Lo interesante es que este proyecto, por vez primera, ya no contemplaba el tradicional y cronológico orden curricular de la historia nacional británica - la historia ya no respondía a un cuerpo diacrónico de conocimientos, sino a una infinita cantidad de más pequeñas estructuras de conocimientos sobre lo que la gente hizo en el pasado. ${ }^{27} \mathrm{~A}$ su vez, el proyecto nace con la idea de ayudar al docente a impartir la materia; en sus propias palabras el Schools Council sugirió que:

Muchos maestros encontrarían que el proyecto les sería útil para proporcionar un estímulo, el apoyo, y materiales para ayudar a revitalizar su propia práctica en general y, más particularmente, para que les ayude a fomentar una mayor participación de los alumnos en su estudio de la historia. ${ }^{28}$

El proyecto significó una reconstrucción completa del currículo, y de la propia historia como asignatura, un auténtico replanteamiento de la filosofía de su enseñanza en las escuelas. ${ }^{29}$

27 L. Symcox y A. Wischut, National History Standards, p. 3.

28 A new look at history, p. 3.

29 A new look at history, p. 4. 
El currículo que se desarrolló era completamente innovador; ahora se ceñía a las necesidades del discente, en consonancia con el modelo constructivistas de adquisición del conocimiento, ubicando al discente el centro de atención. Este currículo resultante, denominado como "a modern world study" permitió a los discentes entender su mundo mediante el estudio en profundidad de una selección de temas que escogidos de forma sincrónica les permitiría comprender el mundo de otras épocas mediante la comprensión de los cambios y las continuidades, así como entender las causas. ${ }^{30}$ Había nacido la "Nueva Historia". De esta manera, la historia se acercaba al alumno, a su alrededor, a su vida cotidiana, haciéndola más útil.

En definitiva, el nuevo currículo ya no consistía en un bloque de hechos históricos, sino de conceptos básicos propios del pensamiento histórico: las evidencias, la continuidad y el cambio, la causa y la empatía. Y lo más importante, la historia se convirtió en una forma de razonar y pensar, un método de investigar para crear imágenes del pasado, ${ }^{31}$ como se verá más adelante, Ilamados conceptos del pasado, incentivándose con ello la reflexión frente a la memorización.

Esta nueva forma de enseñar la historia, ya desprovista de la influencia de la política, permitió a los educadores centrarse más en los desarrollos curriculares dirigidos a incentivar el pensamiento histórico, el cual posibilita la comprensión del pasado mediante la evaluación

30 L. Symcox y A. Wischut, National History Standards, p. 4-5.

31 L. Symcox y A. Wischut, National History Standards, p. 3. de fuentes y la posterior reflexión encaminada a entender el hecho histórico. Mientras, paralelamente al modelo británico, en los Estados Unidos y en Canadá se crean grupos de trabajo encaminados a dar un nuevo sentido a la enseñanza de la historia. En estas reuniones, los educadores se plantean ahora preguntas tales como: ¿Qué puede hacer la historia por el pueblo? ¿Cómo puede el pensamiento histórico ser útil si no hay ya objetivos políticos preconcebidos $u$ objetivos ideológicos a los que servir? ${ }^{32}$

Qué duda cabe que aún hoy en día el pulso entre los que apuestan por una enseñanza de la historia más social, más integradora, y los que apuestan por un enfoque más nacionalista, más etnocentrista, sigue vigente. Por lo tanto, no se puede decir que el canon haya desaparecido por completo, pero sí que tiene su alternativa y que no son pocos los que apuestan por ella; el pensamiento crítico o la multiculturalidad, como conocimiento del otro-como ya indicó el informe de la UNESCO de 1996, ${ }^{33}$ son ya ineludibles para cualquier currículo.

\subsection{Aproximación didáctica a la historia social}

\subsubsection{Enfoques de la historia social}

Tras lo expuesto, se entiende que el desarrollo de un enfoque en materia de didáctica de la historia plantea la siguiente dicotomía, o bien:

32 L. Symcox y A. Wischut, National History Standards, p. 3. 33 UNESCO, La Educación encierra un tesoro, París, Unesco, 1996, p. 33. Recuperado de http://unesdoc.unesco.org/images/ 0010/001095/109590so.pdf 
a) Plantear un marco de referencia que promueva el pensamiento histórico, o

b) Plantear un modelo canónico que promueva la ciudadanía y el patriotismo.

Sobre la idoneidad del uno o del otro se ha discutido mucho, partiendo de dos grandes debates:

a) El debate político: ¿cómo se concilia la globalización con la función de ciudadano de una nación-estado?

b) El debate educativo: ¿es obligado realmente crear un marco de referencia educativo? Si la respuesta es sí, ¿qué tipo de marco de referencia debería ser? y ¿cómo relaciona este marco de referencia el conocimiento canónico y el conocimiento de la historia como un todo?34

Estas cuestiones fueron planteadas en la mesa redonda que se celebró en Utrecht en 2006. En esta conferencia se planteó la siguiente ponencia de la mano de Kaat Wils, Ross Dunn y Linda Symcox cuyo título sería: New Curricula in a Post National World, y en ella se expusieron diferentes opciones para el diseño de un nuevo currículo, para un mundo post nacional. ${ }^{35}$

Las conclusiones fueron las siguientes:

- Huir del canon, aunque, no obstante, un cierto "marco" es aceptable y útil para usar en clase; incluso se puede partir de criterios propios del profesor Wilschut, Van Straeten y Van Riessen. En este sentido, recomiendan,

34 L. Symcox y A. Wischut, National History Standards, p. 5.

35 L. Symcox y A. Wischut, National History Standards, p. 7. como marco contextual, el estudio de los acontecimientos, personajes y hechos significativos, por ejemplo las guerras, los grandes hitos, etc., sin olvidar el estudio de las biografías.

- Incluir las lecciones en un contexto de la historia del mundo. La idea es preparar a los discentes como ciudadanos del mundo, siempre predominando el presente, sin caer en el error de hacer una historia poco profunda, poco atractiva. Mirar más allá de lo local, a lo multicultural a efectos de involucrar a todos los discentes de la clase. La idea clave es el contraste de ideas, de enfoques involucrando a las diversas culturas que puedan haber en clase considerándolas como "miniteorías", añadiendo distintos enfoques, distintos puntos de vista sobre el mismo hecho histórico a trabajar en el aula.

La autora propone particularmente un enfoque contrario al canónico de base nacionalista, siendo la suya una propuesta metacognitiva y esencialmente cosmopolita:

- El currículo debe de tratar a la historia como un asunto global, no nacional.

- Usar los filósofos, historiadores y sociólogos de la llustración por sus ideas sobre la globalización.

- La historia no debe confinarse en un marco de nación-estado.

- Plantear enfoques tales como: 
- El cultural

- El social

- El económico, etc. Algunos de ellos basados en el concepto de MundoSistema; la antropología, la migración o los cambios económicos. Otros tienen en cuenta las razas o el género, pero todas tiene que aportar y deben ser trabajados en conjunción con otras ramas del saber: la geografía, el medio ambiente o la Historia Social. Lo importante es tener en cuenta la dimensión humana; que no quede subsumida en un gran esquema.

- Poner el acento en la justicia social.

- Se entiende como justicia social el hecho de poner al hombre en el centro, antes que la nación-estado.

- Se entiendeque la Historia tiene un servicio social y cívico que forma al estudiante no solo como ciudadano, sino también con respeto al planeta a sus habitantes e incluso a la biosfera a la que pertenece. ${ }^{36}$

No obstante, este fin de la idea del estadonación noimplicauna renunciaala nacionalidad de uno. La filósofa norteamericana Martha Nussbaum, gran defensora del pensamiento crítico, lo ve completamente compatible. ${ }^{37} \mathrm{En}$ primer lugar Nussbaum plantea el hecho de que los discentes deben ser animados a sentirse cómodos en identificarse con su familia, con su etnia, género, religión y las identidades locales, pero sin olvidar su pertenencia al

36 L. Symcox y A. Wischut, National History Standards, p. 43-44.

37 L. Symcox y A. Wischut, National History Standards, p. 45. género humano. Pese a la ambigüedad de la propuesta, Nussbaum plantea una solución: la ciudadanía flexible, que debe ser enseñada en dos partes:

- Los alumnos deben aprende cómo sus identidades, sus culturas, están conectadas entre ellas. De esta manera, deben ver que las antiguas fronteras, con los actuales movimientos de gente, productos y capitales, sirven ya para poco.

- Los alumnos deben de aprender a pensar en este nuevo mundo de intereses compartidos.

Otra de las contribuciones a la nueva didáctica de la historia la podemos encontrar en el denominado proyecto EUROCLIO. Esta organización de docentes de la asignatura de Historia nace en 1992, por encargo del Consejo de Europa, y mediante una representación en 50 países, incluido España, a través de 65 organizaciones de educadores, contribuye desde su génesis mediante sus programas de formación y trabajos a innovar en la Didáctica de la Historia enfatizando el pensamiento crítico, la multiperspectividad, el mutuo respeto y la discusión de temas históricos controvertidos. ${ }^{38}$ Su apuesta, como veremos seguidamente, va dirigida a erradicar el canon de los currículos nacionales. Seguidamente se expone de forma sucinta su Manifiesto, de 15 puntos, sobre la educación de alta calidad en historia, patrimonio y ciudadanía. ${ }^{39}$

38 EUROCLIO, La Haya, European Association of History Educators, 1992. Recuperado de http://euroclio.eu/manifesto/

39 EUROCLIO, La Haya, European Association of History Educators. 
- Previniendo el mal uso del pasado. Complejidad - Multiperspectividad Pensamiento crítico

- Estimular tanto la idea de que no hay un único pasado, como que existen múltiples capas e interpretaciones del mismo. Además, debe incentivarse el pensamiento crítico.

- Deben deconstruirse los mitos históricos ${ }^{40}$ y los estereotipos ayudando tanto a los docentes como a discente a preguntarse sobre su propia lógica así como sobre sus expresiones culturales.

- Hay que incentivar la percepción de un pasado diferente que depende de los antecedentes sociales, generacionales y sexuales de la persona, así como de las etnias y de las comunidades lingüísticas y religiosas.

- Se tiene que abordar temas sensibles y controvertidos de una manera responsable. De este modo se evita las visiones unidireccionales, parciales, y politizadas del pasado, evitando, para ello, el uso de un lenguaje emotivo, subjetivo y hostil promoviendo la imparcialidad en clase.

- Se debe promover la reconciliación en sociedades divididas desarrollando la empatía y la capacidad de discrepar sobre interpretaciones del pasado, evitando recurrir al odio o a la violencia.

40 El modelo tradicional de enseñanza de la historia parte por un lado de la explicación del sufrimiento de la nación y por otro del orgullo nacional, evitando, muchas veces, a hablar sobre el dolor causado a otros y las historias de los territorios que no coinciden con las narrativas nacionales.
Promoviendo un acercamiento inclusivo al estudio del pasado. Diversidad - Diálogo Igualdad

- Hay que ayudar a los discentes a comprender el mundo en el que viven y respalda su orientación para el futuro. El estudio del pasado es una herramienta para el desarrollo de la conciencia política y cívica.

- La enseñanza de la historia debe abarca las múltiples dimensiones del estudio del pasado: política, social, económica, cultural y medioambiental así como el análisis de acontecimientos clave tanto los hechos de largo alcance relevantes como los relativos a la vida cotidiana, naturaleza, género, derechos humanos e inmigración.

- Laenseñanza de lahistoria debedesarrollar los valores humanos, creencias, actitudes y tendencias como la democracia, la tolerancia, el respeto por los derechos humanos, la comprensión mutua, la cohesión social, la solidaridad, la libertad, el amor y la amistad. Pero también debe abordar conceptos negativos como estereotipos, prejuicios, sesgos, xenofobia, racismo, violencia y odio, con la idea de que el discente reflexione sobre ellos.

- Debe promoverse la cohesión y el dialogo intercultural e interreligioso.

- Una educación en historia de alta calidad debe utilizar la historia del entorno como un medio para expresar una clara comprensión sobre el pasado prestando atención al patrimonio como acceso a ese pasado, a través de legados tangibles e intangibles. 


\section{- Avanzando en innovación educativa.} Compromiso-Competencias-Autonomía

- Debe basarse en las competencias, incluyendo aspectos cognitivos (conocimiento), funcionales (aplicación del conocimiento), personales (actitudes) yéticos (principios que guían las actitudes).

- Debe contribuir al desarrollo de competencias clave como la competencia social y ciudadana, aprender a aprender, la competencia digital o el sentido de iniciativa en el aprendizaje. También las competencias transversales como el pensamiento crítico, la creatividad, la solución de problemas y la toma de decisión.

- Una educación en historia de alta calidad debe desarrollar la comprensión cronológica, el significado de la historia, las evidencias de fuentes primarias, la interpretación, la causa y consecuencia, cambio y continuidad, comparación y contraste, empatía, hechos y opiniones, prejuicios y objetividad.

- La enseñanza de la historia debe desarrollar en el discente la habilidad para comprender y analizar problemas $y$ acontecimientos; la habilidad de reunir, organizar, investigar y evaluar fuentes de una manera lógica y coherente, llegando a conclusiones y generando ideas. A su vez, debe ayudarle a desarrollar la destreza necesaria para expresarse claramente proponiendo ideas y argumentos de una manera precisa.

- Una educación en historia de alta calidad debe incluir estrategias pedagógicas y de evaluación que incitan a un aprendizaje independiente, con motivación y compromiso, así como fomentar el sentido de responsabilidad, la participación activa en clase, el deseo de tomar iniciativas, y estimular la comunicación y cooperación, siempre enfatizando la curiosidad y la habilidad de pensar independientemente y resistir cualquier manipulación.

También dentro del ámbito europeo una de las contribuciones con rango institucional que en materia de la Didáctica de la Historia se han presentado en recientes fechas es el proyecto intergubernamental denominado "Shared histories for a Europe without dividing lines." Del proyecto, realizado por el propio Consejo de Europa y terminado en 2014, surgió una serie de documentos que a modo de libro detallan las ideas básicas que como orientación en esta materia propone el Consejo de Europa.

El proyecto nació con una idea clara: presentar un enfoque de la historia de Europa distinto del tradicional basado en los nacionalismos de los estados. Uno de sus leitmotiv es la defensa de la paz y de la convivencia entre los países que constituyen la Unión Europea; es interesante recordar que justo cuando concluye el proyecto se conmemoraba los cien años del comienzo de la $\mathrm{l}^{\mathrm{a}}$ Guerra Mundial, razón que sirvió de acicate para la búsqueda un enfoque didáctico que buscase la unión pacífica entre los países y la huida de las diferencias representadas, antaño, por los antiguos nacionalismos. En definitiva, el Consejo apostó claramente por una enseñanza de la historia de carácter social. Como punto de partida, 
el Consejo de Europa deja claro su propia idea de lo que representa la enseñanza de la Historia, en particular a la gente joven. ${ }^{41} \mathrm{~A}$ lo que añade: el conocimiento histórico y su comprensión ayuda a desarrollar ciertas habilidades, como el pensamiento crítico, desarrollar una menta abierta, y alcanzar conclusiones independientes y tolerantes, ya sean de los tipos transversal o genérico. ${ }^{42}$ Su propuesta, como se ha indicado, va dirigida a la gentejoven, a su preparación para un presente multicultural, globalizado, enfatizando los valores democráticos, en una comunidad que comparte idiomas y religiones distintos no únicamente dentro del ámbito europeo, sino de todo el globo.

De los documentos que resultaron del proyecto se desprende un enfoque claro en la línea con lo expuesto por el grupo EUROCLIO y los trabajos del "New Curricula In a Post National World" o de Nussbaum. Para el Consejo de Europa, la enseñanza de la Historia en este milenio debe de contemplar:

- Unir al pueblo, más que dividirlo.

- La historia debe de ser una herramienta para la paz, para la reconciliación, la tolerancia y la comprensión en lo relativo a la migración o a la inmigración.

41 A la pregunta que se plantea ¿qué hace que la enseñanza de la historia sea tan esencial en el siglo XXI? responde con que la historia da la posibilidad a las nuevas generaciones de viajar en el tiempo, además de aprender sobre el pasado, permite evaluar mejor el presente tanto desde el punto de vista de la política como de lo social. En Shared histories for a Europe without dividing lines, Bruselas, European Council, 2014, p. 4.

42 Shared histories for a Europe without dividing lines, Bruselas, European Council, 2014, p. 5. Recuperado de http://www.coe.int/t/ dg4/education/historyteaching/Projects/SharedHistories/Shared\%20 Histories_Spanish.pdf
- La historia debe ser reflejada en toda su complejidad, sin crear imágenes de un enemigo.

- La enseñanza de la Historia debe mostrar la multiprespectividad, y presentar diferentes puntos de vista.

- Eliminar prejuicios y estereotipos.

- La enseñanza de la Historia debe usar métodos innovadores basados en el diálogo.

- La historia debe de jugar un importante rol en el aprendizaje de ciudadanos responsables, y desarrollar el respeto por todos los tipos de diferencias en una sociedad democrática. ${ }^{43}$

Para su puesta en práctica, el proyecto se centró en aspectos concretos, con la idea de concernir a un máximo número de estados miembros, cuyos objetivos serían presentar claramente el concepto de historias compartidas. Los temas propuestos son:

- El impacto de la Revolución industrial

- El desarrollo de la Educación

- Como se reflejan los derechos humanos en el arte

- Europa y el mundo. ${ }^{44}$

Antes de terminar este apartado, es interesante plantear la siguiente pregunta ¿Qué se entiende por historia social? Podemos definir que la historia social es aquella que habla de la familia, de las formas de organización de la población, del trabajo, de la perspectiva de género, de la vida cotidiana, del mundo rural y urbano, de la interculturalidad, de las

\footnotetext{
43 Shared histories for a Europe without dividing lines, p. 5.

44 Shared histories for a Europe without dividing lines, p. 5.
} 
migraciones y de la violencia en todas sus vertientes $\mathrm{O}$ el conflicto. ${ }^{45}$ La historia social es muy antigua al surgir ya en el siglo XIX como alternativa a la historia de los grandes personajes y hechos heroicos, pero su momento álgido lo encontramos en torno a 1945 con las nuevas tendencias dirigidas hacia el estudio de las estructuras sociales y las diferencias y semejanzas entre grupos. Fue en los años 70, por la influencia de los Annales, cuando la historia de la vida cotidiana rompe con las tendencias anteriores. Desde los años 1980, los historiadores marcaron un giro significativo a lo hasta la fecha establecido; frente a las visiones estructuralistas, aparece la historia de la familia, la historia de la mujer, la historia desde abajo, la sexualidad, la prostitución, la marginación, la pobreza. En este punto, aparecen las microhistorias, como un estudio más profundo de la historia, como resultado de la anteposición del individuo frente a las estructuras; el hombre y sus vivencias marcarán el camino del historiador. ${ }^{46}$ En pleno postmodernismo, la historia social gana espacio; la pobreza o la cultura popular, ésta apoyada en la dimensión antropológica. ${ }^{47}$ La postmodernidad, como vemos, trajo nuevos contenidos, pero además abrió el paso al análisis de nuevos factores sociales: la vida cotidiana, como ya se ha visto, el vestido, la familia o la alimentación, o

45 Cosme Gómez y Pedro Miralles, "La enseñanza de la Historia desde un enfoque social" en Proyecto CLIO, History and History teaching $n^{\circ}$ 39, Murcia, Universidad de Murcia, 2013, p. 1. Recuperado de http://www.ub.edu/histodidactica/images/ documentos/pdf/La_enseanza_historiasocial.pdf

46 C. Gómez y P. Miralles, "La enseñanza de la Historia desde un enfoque social", Pp. 3-5.

47 C. Gómez y P. Miralles, "La enseñanza de la Historia desde un enfoque social", p. 1. cuestiones como la familia, el matrimonio, el parentesco, el envejecimiento, la dependencia, etc. ${ }^{48}$

Gómez y Miralles plantean los beneficios de la inclusión del enfoque social en las aulas de Historia:

- Fomenta el pensamiento crítico y desarrolla los valores cívicos.

- Ayuda a potenciar la participación activa y democrática en los alumnos.

- Desarrolla actitudes de aceptación de la alteridad: la tolerancia, el respeto, la empatía, la ausencia de rechazo sistemático a nada ni a nadie. $^{49}$

Una correcta enseñanza social de la historia debe girar en torno al análisis de las formas de relación, organización y reproducción social, claves para entender las estructuras y evolución de las sociedades y sus procesos de cambio.

\subsubsection{Metodología para la enseñanza de la historia social.}

Hasta ahora se ha visto el enfoque para una didáctica renovada de la historia que se aparta del canon clásico y que se dirige más a lo social y a la búsqueda de la formación del individuo como miembro de la colectividad humana. Pero para este nuevo enfoque hace falta una metodología también renovada, con una nueva perspectiva en la enseñanza de la historia que suponga la

48 C. Gómez y P. Miralles, "La enseñanza de la Historia desde un enfoque social", p. 7.

49 C. Gómez y P. Miralles, "La enseñanza de la Historia desde un enfoque social", p. 7-8. 
transformación de los métodos de aprendizaje..$^{50}$ Esté método, como indica Carretero, debe estar orientado a reflexionar en términos históricos sobre la construcción de lo "propio" y del "nosotros", pero analizando diferentes regímenes de comprensión que abran el enfoque desde la mirada del otro a la mirada hacia el otro. ${ }^{51}$ Con el afán de buscar la claridad expositiva se desglosará inicialmente los elementos básicos, de obligado tratamiento individualizado. Se hablará de la investigación en la historia partiendo de las fuentes, el pensar históricamente y del factor cognitivo, para finalizar con la exposición de la metodología propia de la enseñanza renovada de la historia.

\subsubsection{La investigación en la metodología de la historia social.}

Si buscamos la etimología de la palabra de origen griego Historia, la Magistra Vitae de Cicerón, encontraremos que su significado es preguntar o inquirir. Se dice que el primero en usarla fue Heródoto, en el sigloZA.C. El conocido como el Padre de la Historia, con la idea de hacer un estudio sobre las Guerras Médicas, viajó por el Egeo preguntando a los habitantes de aquellos lugares sobre sus costumbres y tradiciones. En definitiva, lo que hizo Heródoto es hacer una investigación. Por esta razón se entiende que la historia es investigar, investigar a través de las

50 C. Gómez y P. Miralles, "La enseñanza de la Historia desde un enfoque social”, p. 8.

51 Mario Carretero y Manuel Montanero, "Enseñanza y aprendizaje de la Historia: aspectos cognitivos y culturales" en Fundación Infancia y Aprendizaje, Madrid, Universidad Autónoma de Madrid - FLACO (Argentina), Universidad de Extremadura, 2008, p .134. Recuperado de http://www.histodidactica.es/articulos/pp. \%20133142.\%20CARRETERO.pdf. evidencias, como hizo Heródoto, con la intención de dar respuesta a una o a varias preguntas planteadas al inicio de la investigación. En clase, será el discentequiendesarrolleesainvestigación. Este punto es clave puesto que no se trata de que el docente imparta unos conocimientos, sino que sea los discentes los que descubran la respuesta, siguiendo las bases constructivistas relativas a la construcción del conocimiento. ${ }^{52}$ Esta investigación puede llevarse a cabo en sucesivas clases, y siempre recomendaremos que se haga en modo grupal.

Y por su lado ¿qué son las evidencias? Las evidencias, o fuentes, son testimonios de los "informantes" (que pueden ser también: objetos, edificios, imágenes, etc.) que fueron testigos de los contenidos que se estudian. Las fuentes deben ser contrastadas con otras de otros lugares ya conocidas y estudiadas; son pistas que por comparación con las fuentes estudiadas, permiten ubicarlas, datarlas o simplemente contrastarlas. ${ }^{53}$ Como se ve, el discente tiene que aprender a criticar estas fuentes, pero ¿qué planteamientos de partida se debe tener en cuenta para trabajar correctamente con las evidencias y la consiguiente investigación?

En primer lugar, como ya se ha planteado, el discente debe reflexionar críticamente sobre las cuestiones históricas, y poner en duda las evidencias, o sea, las fuentes, que sustentan el hecho histórico, como se verá cuando tratemos la situación-problema. Por tal motivo, Kitson,

52 Alison Kitson, Susan Steward y Chris Husbands, Didáctica de la Historia en Secundaria Obligatoria y Bachillerato, Madrid, Ediciones Morata, 2015, p. 85.

53 J. Prats, Enseñar Historia, p. 19. 
Steward y Husbands plantean unas premisas a seguir a la hora de plantear la investigación con las fuentes disponibles:

- La investigación debe de partir de una pregunta.

- Los alumnos son los que deben de hallar la respuesta a esta pregunta, siguiendo un modelo constructivista (descubrimiento por investigación).

- Una buena pregunta, que puede ser evidentemente planteada por el profesor, debe de tener "meollo" y "rigor".

- Una buena pregunta de investigación debe captar el interés y la imaginación de los discentes.

- La pregunta debe situar el concepto, proceso histórico o pensamiento en el primer plano de los alumnos.

- La pregunta debe conducir a una actividad que debe ser tangible, animada, significativa y entretenida. ${ }^{54}$

Para analizar estas evidencias Kitson, Steward y Husbands proponen que el discente evalúe estas evidencias mediante unas preguntas, a saber:

- ¿qué puede(n) decirnos... sobre...?

- ¿podemos estar seguros de que...?

- ¿por qué es difícil decir...?

- ¿Cuánto puede(n) decirnos... sobre...?55

54 A. Kitson, S. Steward y C. Husbands, Didáctica de la Historia en Secundaria Obligatoria y Bachillerato, p. 85.

55 A. Kitson, S. Steward y C. Husbands, Didáctica de la Historia en Secundaria Obligatoria y Bachillerato, p. 87.
Los mismos autores recomiendan que se parta de algo; cuando los dicentes tengan algún conocimiento sobre el tiempo, el lugar y el contexto, se puede empezar a investigar las cuestiones sobre ese hecho concreto. Es el momento de plantear la pregunta de investigación que dirigirán al discente a construir una explicación del pasado. No obstante, esta investigación que conduce a la comprensión del hecho histórico debe realizarse desde la perspectiva del pensamiento histórico, que se verá seguidamente.

\subsubsection{La reflexión en el aprendizaje histórico.}

Sin ser nueva, el concepto de pensamiento histórico ha cobrado últimamente gran importancia de la mano de autores como Prats y Santacana, Carretero, Santisteban, o Seixas y Norton, entre otros, frente al tradicional método memorístico de enseñar la historia. Se parte de la premisa de que para comprender la historia hay que pensar históricamente, dejando a un lado, como decimos la mera memorización de nombres, hechos o fechas.

Pero ¿qué significa pensar históricamente? Se podría definir el pensamiento histórico como el procedimiento por el cual se entiende el pasado - cómo se interpreta el hecho histórico-, mediante la evaluación y crítica de las evidencias, como fuentes de información, y mediante los procesos mentales propios de la comprensión histórica. Es decir, por un lado se nos plantean preguntas tales como ¿Por qué? ¿Dónde? ¿Cómo?, etc., con la intención de ubicar el hecho histórico, partiendo de las fuentes disponible, 
y por otro lado aplicamos ciertas destrezas mentales que permiten comprender el hecho histórico concreto, es decir darle sentido. Para Seixas y Norton, cuando el docente enseña el pensamiento histórico le está suministrando al discente la posibilidad de pensar más allá de la inmediatez. Le da la posibilidad de comprender la interacción entre las causas de los hechos históricos, partiendo de las influencias de las acciones de los actores históricos, y el contexto social, político o económico dado. A su vez, permite al discente comprender las interacciones entre este contexto, con su capacidad de influencia, y los personajes implicados. ${ }^{56}$

Para Arteaga y Camargo, al respecto de las fuentes como punto de partida, la comprensión histórica permite al discente:

- Reconocer a la historia como una disciplina que permite comprender procesos ocurridos en el pasado (no vivenciales), así como sus relaciones con el presente.

- Plantear interrogantes e hipótesis, identificar evidencias y validar argumentos en torno a los procesos del pasado y sus relaciones con el presente.

- Comprender de manera reflexiva el nivel de relevancia de los hechos, personajes y/o acontecimientos históricos en cuestión, a partir de conceptos históricos de segundo orden, el manejo de fuentes históricas y el debate en grupo.

56 Peter Seixas y Tom Norton, "The big six Historical Thinking Concepts" en Nelson Education, Toronto, 2013, p. 104. Recuperado de https://secondarysocialscience.wikispaces.com/file/view/ Reading13_Seixas_Causation.pdf
- Debatir, a partir de las evidencias planteadas, las diversasy quizás conflictivas historias sobre el pasado planteadas por los historiadores, 0 los testigos de los hechos.

Según Kitson, Steward y Husbands, también en relación con las fuentes, por ejemplo, indican que pensar históricamente significa:

- Ser capaz de analizar fuentes del pasado contextualizándolas.

- Ser capaz de seleccionar críticamente las fuentes con el fin de construir una explicación.

- Comprender el estatus y las limitaciones de esas explicaciones.

Además, estos autores añaden que el pensamiento histórico implica a su vez:

- Comprender la naturaleza de la evidencia (que nace en el historiador).

- Comprender que las personas del pasado no eran como las actuales.

- Comprender el cambio que acontece con el tiempo y su influencia en el presente.

- Comprender las interpretaciones históricas.57

Para Santisteban, mediante el pensamiento histórico se dota al discente de una serie de instrumentos de análisis, de comprensión o de interpretación que le permiten abordar el estudio de la historia con autonomía y construir su propio pasado, a la vez que contextualiza y juzga los hechos pasados, cuyo objetivo es servir

57 A. Kitson, S. Steward y C. Husbands, Didáctica de la Historia en Secundaria Obligatoria y Bachillerato, p. 75. 


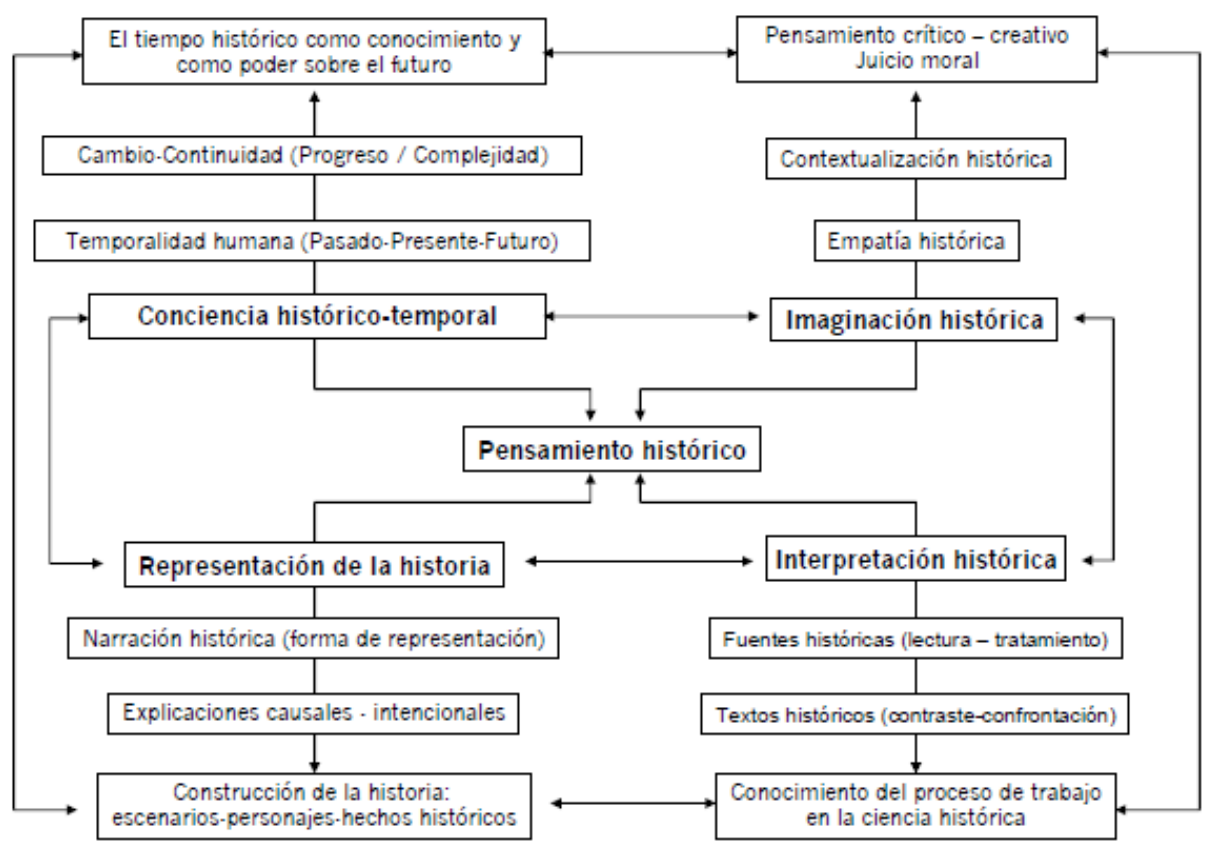

Figura 2. F. Santisteban, "La formación de competencias de pensamiento histórico", p. 7.

a la ciudadanía al interpretar el mundo actual y gestionar el futuro. ${ }^{58}$

A su vez el mismo autor presenta el esquema de la figura 2, prestando atención a las interrelaciones entre el pensamiento histórico y las competencias de pensamiento histórico que él desglosa en cuatro, a saber:

- La conciencia histórico-temporal.

- La representación de la historia como la narración y la explicación del pasado, y su reconstrucción.

58 Fernández Santisteban, "La formación de competencias de pensamiento histórico", en Clío-Asociados $n^{0} 14$, Buenos Aires, Facultad de Humanidades y Ciencias de la Educación. Universidad Nacional de la Plata, 2010, p. 3. Recuperado de http://www. memoria.fahce.unlp.edu.ar/art_revistas/pr.4019/pr.4019.pdf
- La imaginación histórica, dividida en: empatía, contextualización, pensamiento crítico y creativo, y el juicio moral.

- Interpretación histórica basada en las fuentes, en la comparación de las mismas..$^{59}$

El esquema se puede desglosar en:

- La construcción de la conciencia históricotemporal. Para Santisteban, la conciencia histórica ayuda a valorar los cambios y las continuidades en el tiempo, los cambios que sucedieron, los que suceden en el presente, los que podrían ser y los que se desean que fueran. Por lo tanto, mediante la conciencia

59 F. Santisteban, "La formación de competencias de pensamiento histórico", p. 2. 
histórico-temporal se relaciona el pasado con el presente y el futuro, incluyendo la prospectiva. Así el estudio del pasado se dirige a la acción política, la producción cultural, la vida cotidiana o a otras dimensiones de las relaciones humanas. En esta fase, como ejemplo de uso didáctico, se puede hacer reflexionar al discente sobre qué futuro quiere, y cómo conseguirlo, incentivando su formación democrática. ${ }^{60}$

\section{- Las formas de representación de la historia.} La narración es la forma representacional típica de la historia, como, por otra parte, indica Rüsen (Rüsen: 2007). Es la trama de la historia. Para Levstik y Barton (1997) la historia es esencialmente narración ${ }^{61}$ y su enseñanza debe comenzar por las formas más elementales de representación, como pueden ser el cuento o la leyenda. Posteriormente se deben introducir de manera progresiva, por ejemplo, el pensamiento crítico, la comparación de interpretaciones históricas presentes en los manuales, el análisis de los juicios de los personajes o sobre los personajes históricos, etc. Como afirma Plá, la enseñanza de la historia debe conseguir que el discente

60 F. Santisteban, "La formación de competencias de pensamiento histórico”, Pp. 8-11.

61 Al respecto de la narración y su relación con la historia, en directa consonancia con lo expuesto en este epígrafe, el filósofo Julián Marías en su "España Ininteligible. Razón histórica de las Españas”, matizó que la historia se había vuelto menos narrativa, más documental, al basarse más en los documentos. La historia, para Julián Marías, tiende a ser una simple relación de datos geográficos, económicos, demográficos, etc., olvidándose de hablar de los personajes. Pero la mera narración tampoco basta; hay que contextualizar y dar razón al hecho de la realidad que envuelve a esos personajes, hay que interpretarlos, hay que entender su "razón vital”. Julián Marías, España Ininteligible. Razón histórica de las Españas, Madrid, Alianza editorial, 1998, p. 37. realice explicaciones históricas, causales e intencionales, donde los personajes, los escenarios y los hechos históricos se sitúen en una trama coherente de la representación. ${ }^{62}$

- La imaginación histórica y el pensamiento crítico-creativo. La imaginación histórica es uno de los instrumentos de la narración histórica. Como indica el autor, no se trata de imaginación sino de dar sentido a la narración histórica; las fuentes muchas veces no siguen un hilo conductor, hay vacíos que Ilena el historiador, que infiere de las fuentes que estudia. Aquí se incluye la empatía, el imaginar "cómo fue", de la cual se hablará con más detalle más adelante. Por su lado el pensamiento crítico fortalece la didáctica de la historia, y apoya la formación del ciudadano crítico. También se incluye el juicio moral, que para Santisteban

- Es lo que se cree que debe ser o no debe ser, algo inevitable en el estudio de la historia. ${ }^{63}$ Aquí se podría complementar este aporte con el comentario de Howard Gardner sobre la necesidad de contextualizar, considerando las emociones a modo de impacto emocional, aquello que queremos que el discente aprenda. Además, constituye un componente importante de la enseñanza de la historia en las escuelas. El juicio moral en la clase de historia puede ser una preparación para la vida democrática.

62 F. Santisteban, "La formación de competencias de pensamiento histórico", p. 12.

63 F. Santisteban, "La formación de competencias de pensamiento histórico", p. 14,16. 


\section{- La interpretación de la historia a partir de} las fuentes. La interpretación histórica es una competencia que, básicamente, necesita de tres tipos de procesos: a) la lectura y el tratamiento de documentos o evidencias históricas; b) la confrontación de textos históricos con interpretaciones diferentes $u$ opuestas; c) la comprensión del proceso de construcción de la historia. ${ }^{64}$

En otras palabras, el pensar históricamente no es simplemente acumular información, sino valorar críticamente las propias fuentes de información, primarias o secundarias, y las interpretacionesideológicasqueinevitablemente realizamos de los acontecimientos históricos. ${ }^{65}$ Por lo tanto, en el aula se debe incentivar que los discentes critiquen la argumentación del autor, que busquen contraargumentos o que debatan. En definitiva, lo que se plantea es realmente que el discente emule la labor de un historiador, ${ }^{66}$ como un investigador - como un detective. ${ }^{67}$ Tras lo expuesto, se plantea la siguiente pregunta: ¿Qué recursos didácticos están disponibles para enseñar a pensar históricamente? Carretero y Montanero dividen estos recursos en dos grupos, a modo de síntesis:

- Los basados principalmente en el texto oral o escrito.

64 F. Santisteban, "La formación de competencias de pensamiento histórico", p. 17.

65 M. Carretero y M. Montanero, "Enseñanza y aprendizaje de la Historia", p. 136.

66 J. Prat y J. Santacana, Didáctica de la Geografía y la Historia, p. 67. 67 María Camino, Antonia Loste, Milagros Martínez, Joaquín Prats, Joan Santacana, Imma Socías y Gonzalo Zaragoza, Taller de Historia. Proyecto Curricular de Ciencias Sociales. Guía didáctica. Madrid, Ediciones la Torre, 1990, p. 14.
- Los basados en información de carácter icónico. ${ }^{68}$

En el primer grupo se ubicaría la clásica explicación verbal del profesor a base de describir los hechos, las fechas y los personajes. Las explicaciones verbales deben motivar la capacidad comprensiva de los discentes en donde se enlazan tanto las ideas como los argumentos que sustentan estas ideas. Sin embargo, una buena explicación debe proporcionar ciertos apoyos que den coherencia al discurso, que ayuden a comprender las relaciones entre las ideas, clarificando o evocando información implícita o conocimientos previos. Para una correcta comprensión del hecho histórico es necesario contextualizarlo; el docente debe proporcionar información que clarifique las intenciones de los personajes o grupo, las razones económicas, sociales, etc., que los envuelve. ${ }^{69} \mathrm{En}$ definitiva, la participación del discente es crucial (con trabajos en grupo, por ejemplo, según Piaget), y su evaluación debe de partir de esa participación.

Por tal motivo el docente debe de plantear cuestiones tales como inferir posibles desenlaces, según los acontecimientos que se estudian, o posibles factores causales que influyeron o que justifiquen el porqué de esa influencia. ${ }^{70}$ Es muy recomendable plantear preguntas tales como ¿qué harías tú si fueras...? o aquellas que

68 M. Carretero y M. Montanero, "Enseñanza y aprendizaje de la Historia", p. 137.

69 M. Carretero y M. Montanero, "Enseñanza y aprendizaje de la Historia", p. 137.

70 M. Carretero y M. Montanero, "Enseñanza y aprendizaje de la Historia", p. 137. 
evocan planteamientos comparativos entre el presente y aquel pasado. Por otro lado, los textos escritos son también fundamentales. Las fuentes pueden ser primarias, producidas en el momento de los hechos, o secundarias producidas con posterioridad. No siempre están claras las diferencias entre fuentes primarias y secundarias pero, en todo caso, en la enseñanza de la Historia el discente debe aprender a interpretar, comparar, clasificar y dar respuesta a alguna pregunta histórica a partir de las fuentes históricas. $^{71}$

Frente a las secundarias, extraídas de los textos educativos, las primarias (tratados, cartas, etc.) presentan cierta dificultad, principalmente por el vocabulario usado, pero en cambio son muy útiles para trabajar el pensamiento crítico; además permite al discente evaluarlos con la idea de ver su grado de imparcialidad..$^{72}$

El otro gran grupo lo forman aquellos recursos tales como el mapa geográfico, las fotografías o el arte, en todas sus expresiones. También se pueden añadir el vídeo, y más recientemente la multimedia. El arte, como fuente de primaria, por su lado, es un excelente medio para una primera aproximación al periodo histórico que da motivo a la actividad en clase, además favorece la madurez intelectual gracias a que propicia el trabajo autónomo, e incentiva el gusto estético. ${ }^{73}$

71 F. Santisteban, "La formación de competencias de pensamiento histórico", p. 17.

72 M. Carretero y M. Montanero, "Enseñanza y aprendizaje de la Historia”, p. 138.

73 J. Prat y J. Santacana, Didáctica de la Geografía y la Historia, p. 90 .

\subsubsection{La cognición en el aprendizaje histórico.}

La comprensión de la historia representa un ejercicio mental complejo para el discente; la historia, frente a las Ciencias Naturales, por ejemplo, presenta la dificultad de no poder ser probada empíricamente, a lo que se añade la multitud de variables que confluyen en el hecho histórico. En definitiva, no se puede aprender historia basándonos en los mismos postulados con los que se aprende matemáticas, o lo que es lo mismo: la historia tiene su propia epistemología, que debe ser enseñada si se quiere que el dicente comprenda el hecho histórico en su totalidad. El discente tiene que ser consciente de cómo se aprende la historia, teniendo en cuenta qué procesos mentales concurren en el proceso de creación del nuevo conocimiento histórico. Por lo tanto, incluir a la historia en el mismo grupo de saberes, con el resto de las demás asignatura, es un error. ${ }^{74}$

La dificultad de la enseñanza de la historia responde a que para comprenderla no es cuestión únicamente de la mera transmisión de la memoria colectiva y del patrimonio cultural, todo ello ubicado en el espacio y el tiempo, sino que además intervienen, para su correcta comprensión, unas representaciones mentales, como se ha señalado, las cuales permiten que el discente asimile el hecho histórico.

Pero ¿qué habilidades del pensamiento o competencias intelectuales son características

74 Frida Barriga, "Una aportación a la didáctica de la historia. La enseñanza-aprendizaje de habilidades cognitivas en el bachillerato", en Perfiles Educativos no 82, 1998, p. 3. Recuperado de http://www. redalyc.org/articulo.oa?id $=13208204$ 
del aprendizaje de la historia? Carretero y Montanero proponen:

- Evaluar las evidencias e interpretaciones.

- Analizar el cambio a lo largo del tiempo.

- Razonar causalmente. ${ }^{75}$

Por su lado, Barriga, de forma complementaria y basándose en los principios psicopedagógicos del enfoque constructivista, propone las siguientes habilidades como habilidades cognitivas de dominio: noción de tiempo histórico, empatía con los agentes históricos, razonamiento relativista, explicaciones históricas y causalidad y pensamiento crítico. De forma condensada, se pueden dividir estas habilidades fundamentales en dos grupos: la capacidad de comprender el tiempo histórico y razonar causalmente, y la capacidad de valorar e interpretar críticamente las fuentes de información histórica.

Como se viene exponiendo, los eventos históricos se suelen encuadrar en una compleja red de fenómenos interconectados, por lo que dificulta su entendimiento. Debido a ello, la tendencia típica del discente es a simplificar las explicaciones causales acerca de los fenómenos históricos priorizando, a veces, los hechos más cercanos a su tiempo, o bien prestando más atención a la línea explicativa principal, despreciando las secundarias. ${ }^{76}$ Otro fenómeno bastante frecuente es la tendencia a valorar el hecho histórico desde el presente, mostrando con ello una falta de empatía histórica que posibilita

75 M. Carretero y M. Montanero, "Enseñanza y aprendizaje de la Historia", p. 135.

76 M. Carretero y M. Montanero, "Enseñanza y aprendizaje de la Historia", p. 135. la intelección de los hechos del pasado, desde la perspectiva de ese mismo pasado. ${ }^{77} \mathrm{O}$ incluso a "personificar la Historia,",8 o sea, dar demasiada importancia a las acciones o intenciones de los individuos sin valorar otros factores o condiciones que motivan estas acciones.

Es interesante el aporte de Kitson, Steward y Husbands sobre la empatía. Para estos autores la empatía significa comprender el pasado en sus propios términos; es importante recordar que para Santisteban era imaginar "cómo fue", mientras que para Domínguez ${ }^{79}$ sería imaginar pero de una "forma controlada". Por ejemplo, para este autor para comprender la decisión de Felipe II al Duque de Alba a Flandes en 1567 al mando de los Tercios, el historiador debería considerar la situación según la veía el rey, sus intenciones y los medios a su disposición para alcanzar tales fines, es decir, el historiador debería introducirse en la persona de Felipe II. No obstante, como complemento ineludible a la empatía, este historiador tiene que entender el peso que tenía la Iglesia en el siglo XVI, y por qué en aquel siglo una situación como esta, entre el rey y sus súbditos, podría conducir a una decisión de este tipo ${ }^{80}$ En definitiva, como

77 F. Barriga, "Una aportación a la didáctica de la historia”, p. 15. 78 M. Carretero y M. Montanero, "Enseñanza y aprendizaje de la Historia", p. 136.

79 Jesús Domínguez, "Enseñar a comprender el pasado histórico: conceptos y empatía", en Infancia y aprendizaje: Journal for the Study of Education and Development 34, 1986, pp.1-21. Recuperado de https://dialnet.unirioja.es/descarga/articulo/2926292.pdf (extraído 10/8/2016).

80 Esta idea entronca con idea que sobre el hecho histórico tenía Carr, para el cual un hecho pasado no llega a ser un hecho histórico hasta que es reconocido como tal por los historiadores. Es decir, la historia no es una simple acumulación de hechos objetivos ya que el historiador no capta estos hechos de forma objetiva. Por lo 
indica el autor, el historiador llega a este punto de comprensión porque desarrolla un modelo mental, en sus propias palabras "un aparato conceptual", distinto al suyo y más cercano al de Felipe II que complementa a la empatía y que sin este "concepto mental", la comprensión del pasado quedaría incompleta.

Partiendo de esta premisa, es importante que el discente comprenda que la vida de hoy en día no debe considerarse como la única normal, ni posible ni siquiera deseable ${ }^{81}$. La empatía tiene un papel muy importante en la construcción del conocimiento histórico y Kitson, Steward y Husbands resumen qué aporta:

- Respalda el uso de las pruebas.

- Influye radicalmente en la evaluación de la motivación y su papel en las causas.

- Permite ser más matizado y auténtico en la forma de hablar sobre el pasado ${ }^{82}$.

Kitson, Steward y Husbands presentan unas preguntas que se pueden plantear en clase para incentivar la comprensión empática:

- ¿Cómo debió de vivirse el hecho de...?

- ¿Qué pensaban las mujeres/hombres...?

- Si fueras un médico ¿qué remedios recomendarías y por qué?

tanto, los hechos históricos, para Carr, provienen en gran medida de testimonios personales, lo que entran de lleno en la subjetividad. En Julián Casanova, ¿Qué es un hecho histórico? Zaragoza, Universidad de Zaragoza, 2013. Recuperado de http://www.juliancasanova.es/ que-es-un-hecho-historico/

81 A. Kitson, S. Steward y C. Husbands, Didáctica de la Historia en Secundaria Obligatoria y Bachillerato, p. 102.

82 A. Kitson, S. Steward y C. Husbands, Didáctica de la Historia en Secundaria Obligatoria y Bachillerato, p. 104.
- ¿Por qué la iglesia medieval era tan importante...? ?3 $^{83}$

Como se ha visto, una de las piedras de toque para la comprensión del hecho histórico es el pensamiento crítico al cual Barriga presta una especial atención. La autora, en primer lugar, define lo que no es el pensamiento crítico: el pensamiento crítico no es simplemente hacer que los discentes expresen su punto de vista en menoscabo del proceso mismo por el cual han llegado a esa opinión, o de la profundidad y calidad de esa misma opinión. $Y$ es que el pensamiento crítico, para la autora, es un tipo de pensamiento de alto nivel, que involucra en sí mismo otras habilidades (como la deducción, categorización, emisión de juicios, etc.), no sólo cognitivas, sino también valoral-afectivas ${ }^{84}$ y de interacción social, y que no puede reducirse a la simple suma o interacción de habilidades puntuales aisladas de contexto y contenido. ${ }^{85}$

Al respecto, se ve como esclarecedora la definición que realiza McMillan por su aporte práctico. Para este autor, el pensamiento crítico involucra el reconocimiento de supuestos y valores, la evaluación deargumentosy evidencias, la realización de inferencias y la posibilidad de alterar los juicios realizados cuando se justifique. Por un lado, implica la posesión de conocimientos, la posibilidad de efectuar una indagación lógica y

83 A. Kitson, S. Steward y C. Husbands, Didáctica de la Historia en Secundaria Obligatoria y Bachillerato, p. 105.

84 En la Dimensión Valoral intervienen los valores que se fomentan dentro de la escuela, en donde el docente tiene un papel fundamental puesto que en su desempeño, el docente manifiesta valores, creencias, actitudes o juicios que influyen en los juicios de los sus propios discentes. Dimensión de la práctica docente, 2012. 85 F. Barriga, "Una aportación a la didáctica de la historia", p. 22. 
razonar convenientemente, pero por otra parte, también requiere de la disposición a considerar los problemas de manera perceptiva y reflexiva. ${ }^{86}$

Por su lado Mayer y Goodchild aportan una variable más, cuando citan que el pensamiento crítico implica evaluar las ideas o los argumentos de los otros, y los propios, ${ }^{87}$ es decir, incentiva el intercambio de ideas, de pareceres y opiniones. $\mathrm{Si}$ la idea capital es la de crear discentes reflexivos, como parte del estilo de aprendizaje, esta última aportación cobra un especial significado, y qué duda cabe que para la enseñanza de la Historia el pensamiento crítico ocupa un puesto prominente. Como colofón es interesante el aporte que sobre este tema realizó en el 2005 la Wisconsin Historical Society y su "A Handbook for Using Historical Documents to Improve Students' Thinking Skills in the Secondary Grades." En este trabajo se recoge las actividades realizadas en los talleres de formadores que en el ámbito de la enseñanza de la historia forman parte de la Sociedad. En su primera parte del trabajo se revisan los elementos del pensamiento crítico relacionados con la comprensión y el análisis de la evidencia histórica. Esto incluye 10 folletos que pueden ser rápidamente adaptados para su uso en clase, así como un conjunto de herramientas técnicas para fomentar el pensamiento crítico y una guía para su evaluación. La segunda parte del manual presenta 20 tipos de modelos de lecciones, cada uno de los cuales se centran en un único documento disponible en la web de la Sociedad. ${ }^{88}$

86 F. Barriga, "Una aportación a la didáctica de la historia”, p. 23.

87 F. Barriga, "Una aportación a la didáctica de la historia”, p. 24.

88 Michael Edmonds et al., History \& Critical Thinking: A Handbook for Using Historical Documents to Improve Students' Thinking Skills
Pese a su importancia, como indica Barriga, en el texto ya mencionado, lo cierto es que no hay grandes estudios sobre el impacto del uso del mismo en el aula, quizás porque se ve como el mero punto de vista del discente. A modo de ejemplo de aplicación del pensamiento crítico en un aula de historia citaremos el siguiente estudio realizado por el historiador serbio americano Carl Kosta Savich. El estudio fue realizado en una High school history classroom en 2009 de Michigan, sobre 150 de origen hispano con bajos resultados académicos. La materia es la Historia de los Estados Unidos. El objetivo era analizar si el uso del pensamiento crítico en clase motivaría a los alumnos, y les permitiría comprender mejor la Historia, frente a consideraciones tales como "la Historia es aburrida". La base metodológica partió de la Taxonomía de Bloom, con su división en niveles de dificultad cognitiva. La estrategia se basó en el aprendizaje cooperativo, clases en puzle (jigsaw approach), búsqueda de evidencias y la dramatización (role play). Las tareas fueron diseñadaspara motivarquelodiscentesevaluaran diferentes puntos de vista y perspectivas. Las conclusiones del estudio fueron esperanzadoras puesto que tras el análisis de los resultados, se comprobó que los discentes eran más capaces de encontrar un correcto significado de la historia cuando ésta se relaciona con la propia vida de los discentes. La experiencia demostró que los discentes desarrollaban la empatía, la simpatía, y la capacidad de ver la complejidad que implica juzgar el hecho histórico, para lo cual intervienen la perspectiva y los puntos de vista. ${ }^{89}$

in the Secondary Grades. Wisconsin Historical Society, 2005. http:// www. wisconsinhistory.org/pdfs/lessons/EDU-History-and-CriticalThinking-Handbook.pdf.

89 Carl Savich, "Improving Critical Thinking Skills in History" en 


\subsubsection{El método.}

La metodología es la base de cualquier propuesta didáctica, puesto que representa la forma de proceder de acuerdo con un plan..$^{90}$ Es decir, es el método el que define la forma de proceder según un plan preconcebido. Con el método se organiza los temas, las actividades, la evaluación e incluso la gestión social en el aula; en definitiva, escogemos, mediante el método, el camino para llegar a una meta. ${ }^{91}$ Todo lo expuesto en los apartados anteriores tiene que organizarse partiendo de un método, que como también se ha visto, si de la didáctica de la historia se trata, debe de definirse partiendo de las necesidades didácticas que esta materia exige teniendo en cuenta la características propias de la enseñanza de la historia; tanto desde el punto de vista del conocimiento de la materia (con su léxico propio, valoración de fuentes, etc. ) como del factor cognitivo (cómo aprender a aprender historia).

En el campo de la historia podemos definir dos grandes tipos de métodos: el expositivo y el aprendizaje por descubrimiento, sin olvidar a la más que posible tendencia actual al eclecticismo. ${ }^{92} \mathrm{El}$ primero hace referencia al método clásico - el de la clase magistral en donde el discente es el receptor pasivo de una serie de información suministrada por el

Networks, an On-Line Journal for Teaching Research $\mathrm{n}^{0}$ 2, Michigan, 2009. Recuperado de http://journals.library.wisc.edu/index.php/ networks/article/download/180/403

90 J. Prat y J. Santacana, Didáctica de la Geografía y la Historia, p. 51.

91 Dolors Quinquer, "Estrategias metodológicas para enseñar y aprender ciencias sociales: interacción, cooperación y participación" en Revista Íber $n^{\circ}$ 40, Barcelona, Editorial Grao, 2004, p. 1.

92 J. Prat y J. Santacana, Didáctica de la Geografía y la Historia, p. 52. docente que asume el papel de agente activo, como director de la clase. Huelga decir que es el más clásico de los métodos usados en la enseñanza de la historia, pero también el menos recomendable, al menos en su estado digamos que puro, como veremos. El docente tras su exposición usa la pregunta como método evaluativo; según la respuesta, sabrá si el discente ha entendido la explicación. Puede usar textos, mapas o cualquier otro medio para apoyar su disertación, incluso puede adaptar la clase para hacerla más interesante, pero en el fondo lo que se le pide al discente es que memorice. Pese a los inconvenientes que presenta este método, lo cierto es que es viable su uso siempre y cuando se abra hacia la participación, como indica Quinquer.

El segundo método hace, en cambio, al discente el centro de la actividad, relegando al docente a un mero mediador el cual posibilita la tarea siendo el mismo discente el que la desarrolla mediante el trabajo individual, o más frecuentemente mediante el grupal. En el método por descubrimiento, o indagativo, de corte constructivista, con el cual el discente descubre, deduce y elabora él mismo explicaciones históricas; este método, su idea, no es otra que permitir que el discente reordene, reelabore y procese la información adaptándose a su propio esquema cognitivo. ${ }^{93}$ Además, es el que mejor se adapta a la diversidad de perfiles psicológicos del alumnado. ${ }^{94} \mathrm{El}$ punto de apoyo de este método indagativo es la resolución de problemas, pero

93 J. Prat y J. Santacana, Didáctica de la Geografía y la Historia, p. 54. 94 G. Tribó, Enseñar a pensar históricamente. Los archivos y las fuentes documentales en la enseñanza de la historia, p. 51. 
considerando unos factores que marcan su buen uso en clase. Prats y Santacana indican cuatro puntos que influyen en un buen planteamiento del método indagativo, a saber:

- La cantidad, complejidad y grado de la organización de los datos proporcionados.

- El contexto en que se inscriben estos datos y su relación con conceptos que el alumno ya tenga más o menos estructurado; hay que tener presente el axioma que reza: "siempre se aprende sobre aquello que ya se sabe".

- Las capacidades cognitivas del alumno, su formación y, sobre todo, la actitud. En este método, si no hay actitud positiva, no hay aprendizaje.

- La adecuación de los conceptos por aprender según las capacidades del alumno. No todos tienen las mismas capacidades a la misma edad. .5

Los mismos autores presentan una lista de formatos prácticos para trabajar esta metodología, a saber:

- Situación-problema. A partir de una pregunta y una exposición de una situación dada, se plantea la resolución de cuestiones que el alumno debe dilucidar

- Estudio de caso único. Se trata de partir de un tema muy acotado y con suficientes datos aprehensibles $y$ analizables que permiten recomponer una explicación.

- Trabajo por proyectos. Se trata de ofrecer la posibilidad de realizar una "investigación" que construya un informe partiendo de un tema

95 J. Prat y J. Santacana, Didáctica de la Geografía y la Historia, p. 55. que desarrollar con pautas adecuadas de planificación, estrategias de observación de la información y preesquemas de redacción.

- Juegos de simulación. Se plantean estratégicas de resolución de problemas en la forma de juego. Esta orientación debe ser considerada con atención por parte de los docente, sobre todo por la proliferación e implementación de juegos "históricos" multimedia e interactivos que proliferan en el mercado.

- Dramatizaciones o simulaciones. Son una actividad clásica que, en los últimos tiempos, se ha convertido en la realización de reportajes en vídeo o representaciones dramatizadas en las que los discentes debe ocupan el lugar de los personajes históricos. ${ }^{96}$

El concepto situación-problema ha sido estudiado por Dalongeville desde el punto de vista del constructivismo y su aplicación en la didáctica de la historia. Al constructivismo y en particular a una de sus figuras clave Piaget, junto a Vygotski, al cual se le debe su aporte a la didáctica de la historia; el surgimiento de conceptos como el espacio, el tiempo, la causalidad, el azar, la relación y la explicación de cómo se pasa de un estadio a otro, han representado un gran aporte a la disciplina. ${ }^{97}$ Por ejemplo, partiendo del supuesto constructivista el discente aprende partiendo de lo que ya sabe; Dalongeville cita los trabajos de Giordan y De Vecchi y su teoría sobre la construcción del saber. Para los autores los discentes no son páginas en blanco, sino que traer representaciones, ya sean

96 J. Prat y J. Santacana, Didáctica de la Geografía y la Historia, p. 55. 97 G. Tribó, Enseñar a pensar históricamente. Los archivos y las fuentes documentales en la enseñanza de la historia, p. 45. 
representaciones del tipo individual o social. ${ }^{98}$ $Y$ estas representaciones son dificultades para construir nuevo conocimiento, puesto que en el fondo representan estereotipos, ideas o creencias que el discente tiene de un determinado hecho histórico. Giordan y De Vecchi establecen cronológicamente cómo se construye este nuevo conocimiento:

- Emergencia de las representaciones, toma de conciencia, por parte del sujeto, de las representaciones que ya tiene.

- Confrontación con una situación-problema que contribuya ampliamente a poner en tela de juicio las representaciones del sujetodiscente.

- Destrucción o reconstrucción de nuevas representaciones que reorganicen las antiguas e integren las nuevas.

- Metacognición de los procesos que el sujeto individualmente y en grupo ha puesto en práctica desde el principio del enfoque pedagógico. ${ }^{99}$

En definitiva, se habla del equilibrio desequilibrio para posteriormente desembocar en un nuevo equilibrio, como constructor de conocimiento. ${ }^{100}$ Por lo tanto, el docente tiene que incentivar en clase situaciones que induzcan al discente a plantearse nuevas representaciones que pongan en duda, o no, según sea el caso,

98 Alain Dalongeville, "Noción y práctica de la situación-problema en historia" en Enseñanza de las Ciencias Sociales ñ 2, Barcelona, Universidad de Barcelona, 2003, p. 4. Recuperado de http://www. raco.cat/index.php/EnsenanzaCS/article/view/126144

99 A. Dalongeville, "Noción y práctica de la situación-problema en historia," p. 5.

100 C. Coll, E. Martín, T. Mauri, M. Miras, J. Onrubia y I. Solé, EI Constructivismo en el aula, p. 81. las que ya tiene; Dalongeville a esto lo llama "disonancia cognitiva."101

¿En qué ayuda la situación-problema en clase de historia? Básicamente a confrontar los distintos puntos de vista de los discentes con la finalidad de crear conocimiento nuevo, que en el fondo es lo que hace el historiador. Como ya se ha comentado, la historia, justamente esa es su dificultad epistemológica, no está constituida por un solo punto de vista, como ya indicó Carr cuando remarcaba la dificultad de alcanzar la objetividad perfecta. Pero, además hay que tener claro que esta pluralidad de puntos de vista es riqueza, una verdadera fuente de conocimiento para el discente y que en una situación-problema, esa pluralidad es, al mismo tiempo, motor y obstáculo que hay que salvar. ${ }^{102}$ De esta manera, con la aplicación de una situación-problema, la clase de historia se convierte en un laboratorio, en donde se trabajan problemas que deben ser resueltos. ${ }^{103}$ El siguiente punto es el estudio de caso, el cual plantea un extraordinario campo de actuación didáctica dando excelentes posibilidades de trabajo, aunque no debe ser la única para presentar el contenido. ${ }^{104}$ Sobre los tipos de actividades/experimentos responden a la tipología del estudio de caso, Prats y Santacana plantean estos puntos:

101 A. Dalongeville, "Noción y práctica de la situación-problema en historia", p. 5.

102 A. Dalongeville, "Noción y práctica de la situación-problema en historia", p. 13-14.

103 J. Prat y J. Santacana, Didáctica de la Geografía y la Historia, p. 72.

104 J. Praty J. Santacana, Didáctica de la Geografía y la Historia, p. 74. 
- Las dirigidas a aprender a formular hipótesis

- Partiendo de un problema, inicialmente sencillo, se plantea unas hipótesis las cuales deben ser demostrables o rechazables según las fuentes que se dispongan.

- Las dirigidas a clasificar fuentes históricas

- Hay que poner al alcance del discente todo tipo de fuentes: orales, escritas, iconográficas o materiales.

- Las dirigidas a aprender a analizar la credibilidad de las fuentes.

- Si se parte de fuentes escritas, hay que incentivar la lectura indagativa. Por ejemplo, si se usa una fuente iconográfica, por ejemplo una pintura, se debe propiciar preguntas tales como: ¿qué vemos en el cuadro? ¿qué representan los personajes que aparecen en él? ¿qué hacen? etc. A la hora de analizar su credibilidad, hay tener en cuenta que hay que analizar todas las fuentes de forma global, planteando distintos enfoques sobre el mismo tema. Ante un texto, se intentará averiguar las condiciones con la que se elaboró y qué relación tiene el emisor con el hecho. Por lo tanto, hay que tener en cuenta el autory la forma con que lo relata.

- Las dirigidas al aprendizaje de la causalidad

- Enfocar el problema de la causalidad histórica significa establecer la correcta comprensión de las relaciones causaefecto, teniendo en cuenta que un acontecimiento puede tener más de una causa y más de una consecuencia.
Además, puede ser que el hecho tenga consecuencias a corto plazo, a largo plazo, directas o indirectas. Las tareas responden a preguntas tales como: ¿Por qué pasó esto? ¿Quién fue el responsable? El resultado debe de ser la elaboración de una teoría explicativa.

- Las dirigidas a iniciarse en la explicación histórica. ${ }^{105}$

\section{Conclusiones}

A través del canon histórico los Estados han inculcado el hecho diferencial entre las naciones mediante el nacionalismo excluyente. Con él, la historia es un catálogo positivista bien definido de hechos gloriosos y de grandes personajes, para que un alumno pasivo aprenda y recite de memoria, sin tener en cuenta los conceptos, ni a las habilidades cognitivas, que dan vida al hecho histórico. Pero en los años 70 en Gran Bretaña aparece una corriente pedagógica la cual vendrá a aportar un nuevo enfoque a la enseñanza de la historia. Con este nuevo paradigma, el canon retrocede y gana terreno la Historia Social, bajo la influencia de la Escuela de los Annales. La historia se acerca al discente quien ya no tiene que memorizar sino comprender, comprender pensando históricamente, o lo que es lo mismo, convertir la información en conocimiento. En este artículo se ha visto como la Historia como asignatura tiene un valor capital en la educación del presente y del futuro de la juventud, al representar un excelente medio para incentivar

105 J. Prat y J. Santacana, Didáctica de la Geografía y la Historia, p. $75-80$. 
el conocimiento de la otredad. Para formar a mejores ciudadanos, más participativos, más democráticos y más reflexivos, en un mundo globalizado. La enseñanza de la historia se complementa con otras ramas del saber: la geografía, la economía, la política o el ecologismo humanista o reconceptualista, se incorporan a la enseñanza de la historia, en donde de forma holística se trata de dar sentido a los acontecimientos de un pasado siempre complejo. Una buena didáctica de la historia debe contemplar la integración de varios métodos; desde el aprendizaje verbal significativo al aprendizaje por descubrimiento. ${ }^{106} \mathrm{El}$ discente ahora investiga, reflexiona y empatiza con los personajes del pasado, un pasado que se relaciona con su presente a través de su familia, de su comunidad, de su país o como miembro de la raza humana. Porque aquello que el discente aprende a partir de una investigación o resolución de un problema lo integra de manera más estable en su memoria comprensiva, y además le ayuda a adquirir habilidades intelectuales adecuadas para construir conocimiento de manera autónoma, ${ }^{107}$ detalle, este último, fundamental para la vivir en la actual sociedad del conocimiento. El constructivismo, las habilidades cognitivas, o la psicopedagogía contribuyen a cambiar la didáctica de la Historia. Una historia, como decimos al principio, que ahora la hacen las personas más comunes, más sencillas, como nos decía Bertolt Brecht sobre aquel obrero que al leer un libro se preguntaba...

106 G. Tribó, Enseñar a pensar históricamente. Los archivos y las fuentes documentales en la enseñanza de la historia, p. 53.

107 G. Tribó, Enseñar a pensar históricamente. Los archivos y las fuentes documentales en la enseñanza de la historia, p. 53.
¿Quién construyó Tebas, la de las siete Puertas? En los libros aparecen los nombres de los reyes. ¿Arrastraron los reyes los bloques de piedra? Y Babilonia, destruida tantas veces, ¿quién la volvió siempre a construir?... La gran Roma está llena de arcos de triunfo. ¿Quién los erigió?

\section{Bibliografía}

A new look at history, Edinburgh, Holmes McDougall Ltd., 1976.

Alcaraz, Amparo. Pastor, Montserrat, "Tendencias de la historia como objeto de enseñanza a través de la Historiografía" en Didácticas Específicas, $n^{0}$ 6, Madrid, Universidad Autónoma de Madrid, 2012 pp. 114-139. Recuperado de: https://repositorio.uam.es/ bitstream/handle/10486/10852/54136_6. pdf?sequence $=1$

Arteaga, Belinda. Camargo, Siddharta, "Educación histórica: una propuesta para el desarrollo del pensamiento histórico en el plan de estudios de 2012 para la formación de maestros de Educación Básica" en Revista Tempo e Argumento, vol. 6, $n^{0} .13$, Florianópolis, Universidade do Estado de Santa Catarina Florianópolis, 2014, pp. 110140. Recuperado de http://www.redalyc.org/ $\mathrm{pdf} / 3381 / 338139190006 . \mathrm{pdf}$

Barriga, Frida, "Una aportación a la didáctica de la historia. La enseñanza-aprendizaje de habilidades cognitivas en el bachillerato" en 
Instituto de Investigaciones sobre la Universidad y la Educación $n^{\circ} 82$, Ciudad de México, Facultad de Psicología, Universidad Autónoma del Estado de México, 1998. Recuperado de http:// www.redalyc.org/articulo.oa?id=13208204

Camino, María. Loste, Antonia. Martínez, Milagros. Prats, Joaquín. Santacana, Joan. Socías, Imma. Zaragoza, Conzalo, Taller de Historia. Proyecto Curricular de Ciencias Sociales. Cuía didáctica. Madrid, Ediciones la Torre, 1990.

Carretero, Mario. Montanero, Manuel, "Enseñanza y aprendizaje de la Historia: aspectos cognitivos y culturales" en Fundación Infancia y Aprendizaje, Madrid, Universidad Autónoma de Madrid - FLACO (Argentina), Universidad de Extremadura, 2008, pp. 133-142. Recuperado de http://www.histodidactica.es/articulos/ pp.\%20133-142.\%20CARRETERO.pdf

Casanova, Julián, ¿Qué es un hecho histórico? Zaragoza, Universidad de Zaragoza, 2013. Recuperado de http://www.juliancasanova. es/que-es-un-hecho-historico/

Coll, César. Martín, Elena. Mauri, Teresa. Miras, Mariana. Onrubia, Javier. Solé, Isabel, El Constructivismo en el aula, Barcelona, Editorial Crao, 1998.

Dalongeville, Alain, "Noción y práctica de la situación-problema en historia" en Enseñanza de las Ciencias Sociales, $n^{0}$ 2, Barcelona, Universidad de Barcelona, 2003. Recuperado de http://www.raco.cat/index.php/Ensenanza CS/article/view/126144
Dimensión de la práctica docente. Blog, 2012 Recuperado de http://dimensiones-dela-practica-docente.blogspot.com.es/p/ valoral.html

Domínguez, Jesús, "Enseñar a comprender el pasado histórico: conceptos y empatía", en Infancia y aprendizaje: Journal for the Study of Education and Development 34, 1986, pp.1-21. Recuperado de https://dialnet.unirioja.es/ descarga/articulo/2926292.pdf (extraído 10/8/2016).

EUROCLIO, La Haya, European Association of History Educators, 1992. Recuperado de http:// euroclio.eu/manifesto/

Facal, Ramón, "La enseñanza de la historia, más allá del nacionalismo" en Ponencias del VI Congreso de la Asociación de Historia Contemporánea, Zaragoza, Universidad de Zaragoza, 2002. Recuperado de http://www. histodidactica.es/articulos/lopez-facal.htm

Gallagher, Carmel, History teaching and the promotion of democratic values and tolerance. Bruselas, Council of Europe, 1996.

García, Ricardo, La Herencia del pasado. Las memorias históricas de España, Barcelona, Galaxia Gutenberg-Círculo de Lectores, 2011.

Gómez, Cosme y Miralles, Pedro, "La enseñanza de la Historia desde un enfoque social" en Proyecto CLIO, History and History teaching $n^{0} 39$, Murcia, Universidad de Murcia, 2013. Recuperado de http://www.ub.edu/ 
histodidactica/images/documentos/pdf/La_ enseanza_historiasocial.pdf

Conzales, Paula, "Concienciahistóricayenseñanza de la historia: una mirada desde los libros de texto" en Enseñanza de las Ciencias Sociales, $n^{\circ}$. 5. Barcelona, Universidad de Barcelona, 2006, pp. 21-30. Recuperado de http://www.redalyc. org/pdf/3241/324127625003.pdf

Kitson, Alison. Steward, Susan. Husbands, Chris, Didáctica de la Historia en Secundaria Obligatoria y Bachillerato, Madrid, Ediciones Morata, 2015.

Michael, Edmons, Jennifer A, Hull. Erika Janik, Keli Rylance, A Handbook for Using Historical Documents to Improve Students' Thinking Skills in the Secondary Grades. Wisconsin Historical Society, 2005. Recuperado de http://www. wisconsinhistory.org/pdfs/lessons/EDUHistory-and-Critical-Thinking-Handbook.pdf

Molina Sebastián, Rodríguez, Raimundo. Sánchez, Raquel, "Investigar, enseñar y divulgar la historia social: la experiencia del Seminario y grupo de investigación Familia y Élite de Poder de la Universidad de Murcia" en Proyecto Clío n³9, Murcia, Universidad de Murcia, 2013. Recuperado de http:// clio.rediris.es/n39/articulos/historiasocial/ MolinaRodriguezSanchez.pdf

Prats, Joaquín, En defensa de la Historia como materia educativa, Barcelona, Departament de Didàctica de les Ciències Socials, Universidad de Barcelona, 2010.
Prats, Joaquín, Enseñar Historia: notas para una didáctica renovadora, Mérida, Junta de Extremadura. Dirección Ceneral de Ordenación, Renovación y Centros, 2001.

Prat, Joaquín. Santacana, Joan, Didáctica de la Ceografía y la Historia, Barcelona, Editorial Grao, 2011.

Ruiz, Cristóbal, La Educación en la sociedad postmoderna: Desafíos y oportunidades, Málaga, Universidad de Málaga, 2009. Recuperado de https://revistas.ucm.es/index.php/RCED/ article/viewFile/RCED1010120173A/15238

Seixas, Peter y Norton, Tom, "The big six Historical Thinking Concepts" en Nelson Education, Toronto, 2013, pp. 104-115. Recuperado de https://secondarysocialscience.wikispaces.com/file/view/ Reading13_Seixas_Causation.pdf

Quinquer, Dolors, "Estrategias metodológicas para enseñar y aprender ciencias sociales: interacción, cooperación y participación" en Revista Íber $n^{\circ} 40$, Barcelona, Editorial Crao, 2004, pp. 7-22.

Santisteban, Fernández, "La formación de competencias de pensamiento histórico" en Clío-Asociados, $n^{0} 14$, Buenos Aires, Facultad de Humanidades y Ciencias de la Educación. Universidad Nacional de la Plata, 2010, pp. 34-56. Recuperado de http://www.memoria. fahce.unlp.edu.ar/art_revistas/pr.4019/ pr.4019.pdf 
Savich, Carl, "Improving Critical Thinking Skills in History" en Networks, an On-Line Journal for Teaching Research, $n^{0}$ 2, Michigan, 2009. Recuperado de http://journals.library. wisc.edu/index.php/networks/article/ download/180/403

Shared histories for a Europe without dividing lines, Bruselas, European Council, 2014. Recuperado de http://www.coe.int/t/dg4/education/ historyteaching/Projects/SharedHistories/ Shared\%20Histories_Spanish.pdf

Symcox, Linda y Wischut, Arie, National History Standards. The problem of the Canon and the Future of teaching History. A Volume in international review of History Education. Alabama, Universidad de Alabama, 2009.

Torpey, John, The Pursuit of the Past: A Polemical Perspective, Vancouver, University of British Columbia, 2001.

Tribó, Gemma, Enseñar a pensar históricamente. Los archivos y las fuentes documentales en la enseñanza de la historia, Barcelona, Cuadernos del profesorado. I.C.E Universidad de Barcelona, 2005.

UNESCO, La Educación encierra un tesoro, París, Unesco, 1996. Recuperado de http://unesdoc.unesco. org/images/0010/001095/109590so.pdf 